\title{
Appel d'articles - Voix plurielles 10.2 (2013)
}

Voix plurielles, revue de l'APFUCC, lance un appel d'articles libres pour son numéro de décembre 2013. Le sujet peut être littéraire, comparatif, (socio-)linguistique ou socioculturel et porter sur des aspects variés dans les domaines français et francophones, ainsi que dans celui des langues de France.

En particulier, mais pas exclusivement, les membres de 1'APFUCC ayant participé au Congrès 2013 à Victoria sont cordialement invité-e-s à envoyer leur communication développée aux normes de la revue.

Les tapuscrits seront soumis à un comité de lecture pour évaluation anonyme.

Le tapuscrit doit être rédigé en français (longueur : 15-20 p., double interligne). Veuillez consulter le site de la revue pour vous informer du format employé.

Les articles seront soumis à Catherine Parayre, Directrice de rédaction (cparayre@brocku.ca), sous Word ou en RTF, au plus tard le 15 septembre 2013.

Voix plurielles est accessible sur www.apfucc.net ainsi qu'à l'adresse suivante : http://brock.scholarsportal.info/journals/voixplurielles

Comptes rendus - Si vous souhaitez écrire le compte rendu d'un ouvrage récent, veuillez prendre contact directement avec la Directrice de rédaction. (Merci de ne pas lui envoyer de compte rendu sans son accord préalable.)

Numéros thématiques - Finalement, la revue serait heureuse d'accueillir des numéros thématiques ou des actes de colloque dans les prochains numéros et vous prie, le cas échéant, de bien vouloir signaler votre intérêt.

Au plaisir de vous lire, La rédaction 